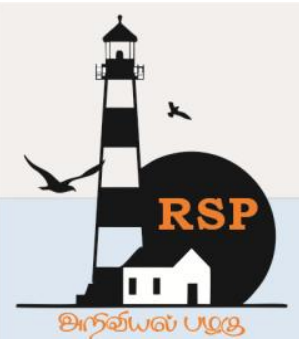

INTERNATIONAL RESEARCH JOURNAL ON ADVANCED SCIENCE HUB

RSP SCIENCE HUB

(The Hub of Research Ideas)

Available online at www.rspsciencehub.com

\title{
Explosion and Fire Resistance of Recycled Constituent Reinforced Concrete Structures
}

\author{
Ayush Meena ${ }^{1}$, Ajay Singh Jethoo ${ }^{2}$, P.V. Ramana ${ }^{3}$ \\ ${ }^{1}$ Research Scholar, Department of Civil Engineering, Malaviya National Institute of Technology, Jaipur- \\ 302033, India \\ ${ }^{2}$ Professor, Department of Civil Engineering, Malaviya National Institute of Technology, Jaipur-302033, \\ India
}

${ }^{3}$ Assistant Professor, Department of Civil Engineering, Malaviya National Institute of Technology, Jaipur302033, India

2020rce9521@mnit.ac.in ${ }^{1}$,asjethoo.ce@mnit.ac.in ${ }^{2}$,pvramana.ce@mnit.ac.in ${ }^{3}$

\begin{abstract}
In the past few decades, the impact of explosions on buildings has been the area of research, mainly because buildings worldwide are increasingly facing the risk of deliberate explosion attacks, accidental explosions, and other forms of related explosion failure. The magnitude of the explosive load generated by most explosions is much higher than the design load of conventional structural engineering. As a result, with the intensification of global terrorist attacks, building owners, government departments, and design professionals have become more aware of the vulnerability and survivability of structures to explosive loads. Although much work on the impact of explosions on infrastructure continues, especially in India, numerical work to test explosives has been restricted. In addition, there are few computational tests for reinforced concrete beam-column joint to withstand explosive loads within a close range with a ruler spacing of less than as mentioned in IS: 1449. This may be due to the unreliable accuracy and relatively low survivability of most tools in this area.
\end{abstract}

Keywords: explosive loads; elevated temperature; explosive yield; Specific heat; Thermal conductivity.

\section{Introduction}

Because the uncertainty and difficulty of terrorist attacks and accidental explosions cannot be predicted, thereis little information on design recommendations and the performance of reinforced concrete structures exposed to explosives. Most of the results are not in the public domain. Civil engineers and others have been looking for solutions and developing inexpensive methods to protect lives and prevent a partial or complete collapse of the structure. Designed to prevent death and injury to residents and improve the survivability of buildings. Therefore, the solution includes improving physical security to increase and maintain clearances and strengthen the building's exterior walls. The preferred choice of materials for explosion-proof structures is based on their availability, relatively low cost, and their inherent ability to absorb the energy generated by explosions. Understanding how components behave in explosive situations is critical to improving the survivability of the structure. The explosion in Jaipur City made researchers aware of the importance of understanding the explosionproof properties of concrete columns.[1-5]. Since such catastrophic events indicate that underground pillars may fail and lead to the gradual collapse of buildings, extensive research has been conducted to study the performance of reinforced concrete pillars under explosive loads, and the testing of 


\section{www.rspsciencehub.com}

live explosives is limited, especially considering the explosiveness Load test. Consider the influence of axial load on the bending performance of the column. This limit applies to reinforced concrete columns exposed to air loads in a narrow range of ratios. Builders and governments are increasingly interested in understanding the vulnerability of their structures to explosive devices and what measures can be taken to improve the survivability of buildings and the people in them. Other design professionals can understand the general characteristics of explosive loads and the expected behaviour of structures exposed to explosive charges and develop new methods and guidelines for buildings that can withstand explosive charges.T. Ngo, et al. (2007) [1] for their study on "Blast loading and Blast Effects on Structures" gives an overview on the analysis and design of structures subjected to blast loads phenomenon for understanding the blast loads and dynamic response of various structural elements.T. Ch. Madhavi et al. (2016) [2] the researchesimpact of precise temperature on concrete powerthrough the partial substitute of the first-class aggregate. Through Study they achieved to recognize the temperature outcomes on concrete throughout publicity of heat, hearth place, climatically modifications happen seasonal version has been investigated through reviewing a few global journals. To investigate the impact of extended temperatures of 100 , two hundred, and $300^{\circ} \mathrm{C}$ with numerous publicity intervals of $4,8,12$ and 72 hours on trial blend specimen.[6-10].

\section{Explosion Phenomena}

Explosion can be described because of the unexpected launch of electricity within side a tiny proportion of second producing excessive stress and heat. Many blasts reassert can reasonharm to the structure, for example, chemical compounds that could react unexpectedly below positive situations and bring about the spontaneous launch of a massive quantity of electricity. Flammable substances shape smoke clouds within side the presence of air that generates an excellent quantity of electricity. Speedy launch of electricity generate through any reason produces a blast wave, for example, bursting of a stress vessel and unexpected segment transition from liquid to gas.

\subsection{Features of Blast Waves}

Fig.1 shows pressure-time history explosion wave.
$P_{O}=$ Pressure of surrounding

$P_{S O}=$ positive side-on overpressureof blast wave

$P^{-}$SO = negative side-on overpressureof blast wave

$P_{r}=$ Reflected overpressureof wave

$i_{S}=$ positive phase-specific impulse

$i_{S}{ }^{-}=$negative phase-specific impulse

$t_{a}=$ stretching timeof wave

$t_{o}=$ positive phase duration of wave

$t_{o}{ }^{-}=$negative phasedurationof wave

Overpressure described as because of the growth in the strain of the environment regarding ambient strain. Free-area loads are the loads produced via an explosion that strikes immediately over the item with no mirrored image and puts off all the gadgets of their route. Free-area load is likewise defined as side-on while the explosion wave contemplated over a wall or different item parallel to its path. [4].

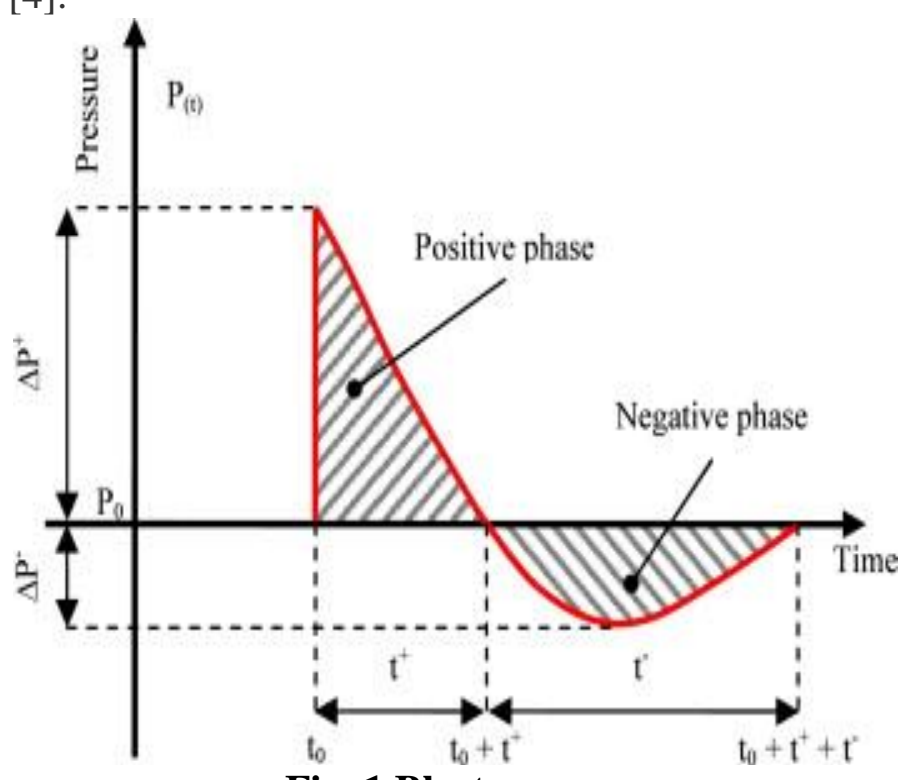

Fig. 1 Blast wave

\subsection{Scaling of factors}

Explosion parameters are generally provided in a scaled shape like pressures, velocity, impulse, times, and lots other. Previous lyit has proven that scaling legal guidelines may be carried out to explosions with comparable geometry within side the identical ambient conditions, same explosive and specific size. Scaling may benefit blast predictions, numerical modelling facts for any explosion, and variant standoff distance patterns.

Scaling may be executed in step with IS: 4991 [3]:

Scaled distance $\mathrm{x}=\frac{\text { Actual distance }}{\mathrm{W}^{1 / 3}}$

Scaled time $t_{0} \quad=\frac{\text { Actual time }}{\mathrm{w}^{1 / 3}}$ 
Where

$\mathrm{W}=$ yield of explosion

\section{Fire phenomenon}

According to the 'National Building Code of India' (Part four Fire and Life Safety-2005), hearth place resistance is an asset of both a detail and fabric of constructing creation. A hearth place can most effectively beginwhile3factors are gift simultaneously: oxygen, flammable substances, and a warmth source. Together, they make up what has usually known as the hearthplace triangle. The first factor will most effectively begin combustion while the irritation temperature is reached [4]. Building substances utilized in creation are of types: Combustible substances will integrate exothermically with oxygen, provide upward push to flame, and unfold the hearth place. Such substances, whether shape a part of the shape or contents of the construction, burn themselves and grow the depth and boom of the hearth place, i.e., it acts as a gas for the hearth place. Examples of such substances are timber and all timber merchandise, synthetic merchandise, fibreboard, strawboard, etc.[11-15]. Non-Combustible substances these substances do now no longer make contributions to the boom of a hearthplace. Still, they will get broken while the temperature reaches an excessive degree wherein fusion occurs, ensuing within side the construction's lack of energy. If such substances are used within side the shape, it could keep the shape's integrity for an extended period and subsequently collapse. Examples of such substances are metal, stone, glass, concrete, clay merchandise, gypsum merchandise, and asbestos merchandise. [16-20].

\section{Thermal properties of concrete}

Experiments have demonstrated that when a material is subjected to various temperatures, its structural qualities can alter. These changes can have a big impact on the outcome of a firedamaged structural investigation. In the event of a fire, structure members can reach temperatures of up to $1000{ }^{\circ} \mathrm{C}$ for an extended length of time.[2123].

\subsection{Specific heat (J/Kg K)[6] \\ $C_{c}(T)=900$ for $20^{\circ} \mathrm{C} \leq \mathrm{T} \leq 100{ }^{\circ} \mathrm{C}$ $C_{c}(T)=900+(T-100)$ for $100^{\circ} \mathrm{C}<\mathrm{T} \leq 200^{\circ} \mathrm{C}$}

$C_{c}(T)=1000+(T-200) / 2$ for $200^{\circ} \mathrm{C}<\mathrm{T} \leq 400^{\circ} \mathrm{C}$

$C_{c}(T)=1100$ for $400^{\circ} \mathrm{C}<\mathrm{T} \leq 1200^{\circ} \mathrm{C}$

4.2. Thermal conductivity $(\mathrm{W} / \mathrm{m} \mathrm{K})$ for $20^{\circ} \mathrm{C} \leq$ $\mathrm{T} \leq 1200{ }^{\circ} \mathrm{C}[6]$

Lower limit:

$k(T)=1.36-0.136\left(\frac{T}{100}\right)+0.0057\left(\frac{T}{100}\right)^{2}$

Upper limit:

$k(T)=2-0.2451\left(\frac{T}{100}\right)+0.0107\left(\frac{T}{100}\right)^{2}$

\section{Pressure on closed rectangular structures}

\subsection{Front face}

When the shock wave strikes a structure's vertical face, it reflects, and the pressure quicklyrises to the reflected overpressure $\left(p_{\text {ro }}\right)$ [3].

Where

$$
p_{\text {ro }}=p_{\text {so }}\left(2+\frac{6 p_{\text {so }}}{p_{\text {so }}+7 p_{a}}\right)
$$

$p_{a}=$ the surrounding pressure $\left(1 \mathrm{~kg} / \mathrm{cm}^{2}\right)$

at time $t$, the pressure applied on the opposite face to the loading direction is called reflection overpressure $p_{r}$ or $\left(p_{s}+C_{d} q\right)$, whichever is greater [3].

$C_{d}=$ drag coefficient

$t_{c}=$ clearance time given by: $t_{c}=$ least of $\frac{3 S}{U}$ or $t_{d}$

$\mathrm{S}=\mathrm{H}$ or $\mathrm{B} / 2$, whatever is the smallest

$\mathrm{U}=$ velocity of shock front $=\mathrm{M} \times \mathrm{a}$

$\mathrm{a}=$ sound velocity in air which may be taken as $344 \mathrm{~m} / \mathrm{s}$

$\mathrm{M}=$ incident pulse's Mach number given by $\sqrt{1+6 p_{\text {so }} / 7 p_{a}}[3]$

\subsection{Rear face}

The standard loading on back face is calculated as shown in Fig.2. (a) The time has been measured from the time the shock wave first struck the structure's front face[3].

The time intervals that are of interest as follows: $\frac{L}{U}=$ from the front to back face, a shock wave travels through time $\frac{4 S}{U}=$ when the pressure on the back facerises [3] 


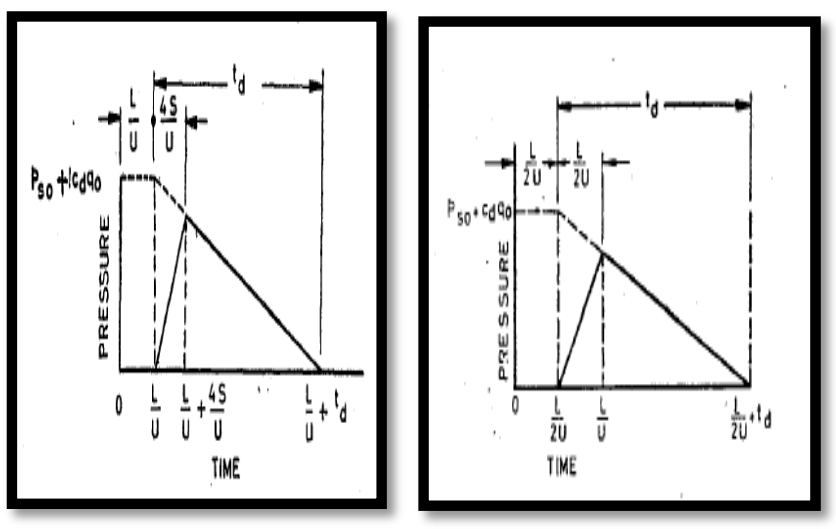

Fig.2. (a): For the back face, Pressure vs. time (b): When $t_{d}>t_{t}$, the average pressure curve

\subsection{Roof and sidewalls}

The variation in average pressure and time for roof and sidesis shows inFig.2. (b). When $t_{d}$ is greater than $t_{d}$, the transit time is takenast $t_{t}=\frac{L}{U}$, and when $t_{t}$ is greater than $t_{d}$, the load on the roof and sides can be modelled as a moving triangle pulse with peak overpressure and time

$\left(p_{s o}+C_{d} q_{o}\right)$ and $t_{d}[3]$.

\section{Result \& Discussions}

The reinforced concrete structure is both stable and long lasting. It has elevated resistance to pressure and tension. It is economical. RCCis almost impervious to warping and rust. It is resistant to fireand other climate conditions. RCC may work with ordinary skilled employees on a worldwide scale and does not require experienced professionals. The following conditions are observed:

Case 1: 10-meter distance from the structure with $400 \mathrm{~kg}$ yield of explosion

Case 2: 20-meter distance from the structure with $400 \mathrm{~kg}$ yield of explosion

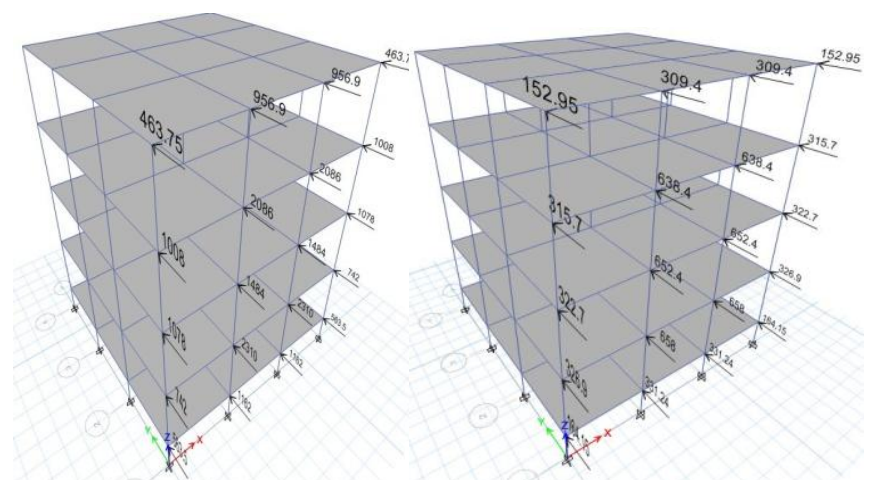

Fig.3. Blast load applied over the structure for case 1 and 2
Case 3: 10-meter distance from structure with 200 $\mathrm{kg}$ yield of explosion

Case 4: 10-meter distance with $400 \mathrm{~kg}$ yield of explosion for 4 bay $\mathrm{X} 4$ bay structure

Case 5: 10-meter distance with $400 \mathrm{~kg}$ yield of explosion for 6 bay X 6 bay structure
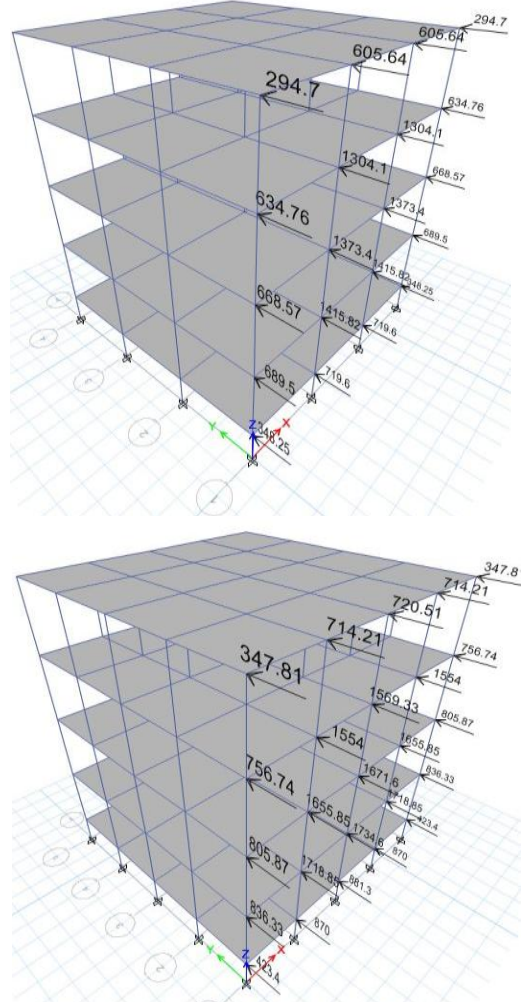

Fig.4. Blast load applied over the structure for case 3 and 4

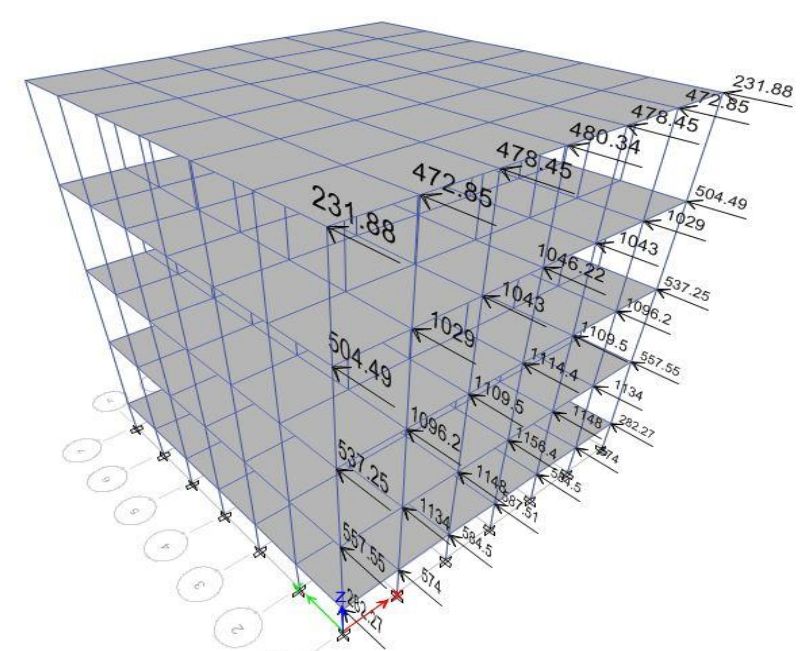

Fig.5.: Blast load applied over the structure for case 5 


\subsection{Load and displacement curves}

Blast load is applied over the structure and after the analysis the structure deform, and the displacement values as shown below

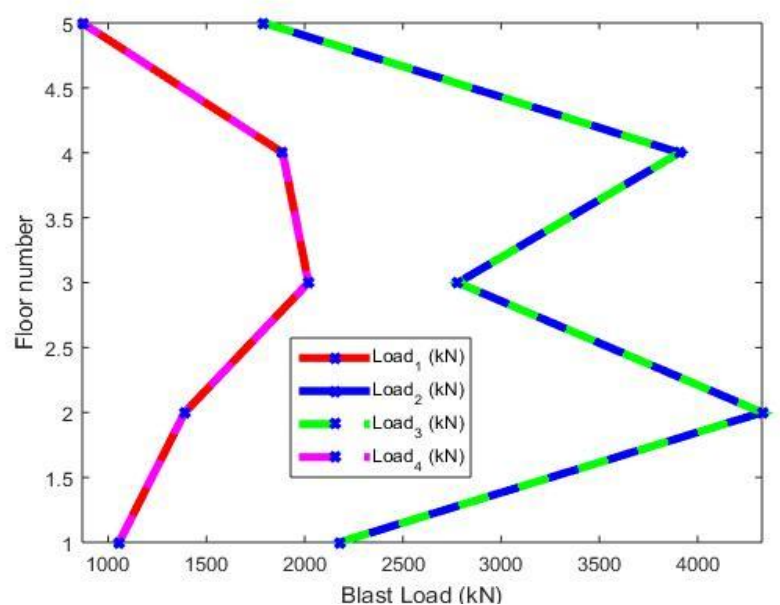

Fig.6. (a) Load vs floor number for case 1
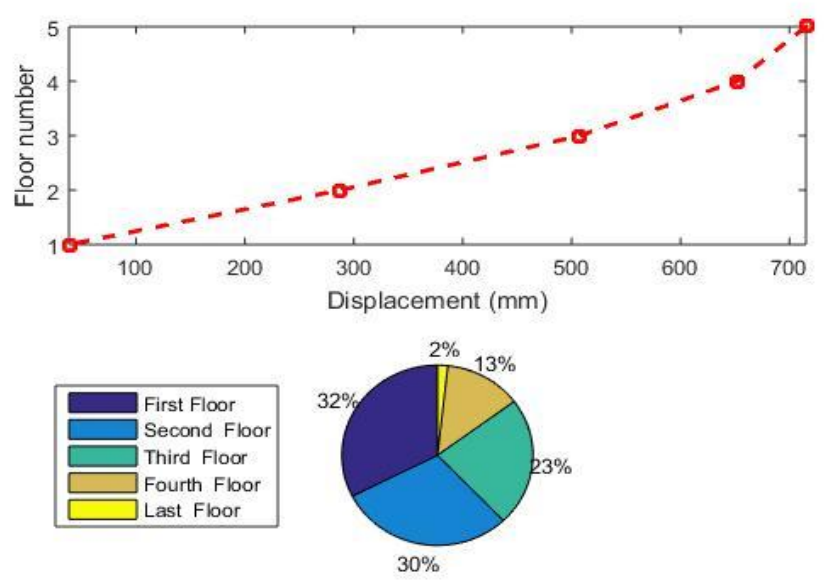

Fig.6. (b) Displacement vs floor for case 1

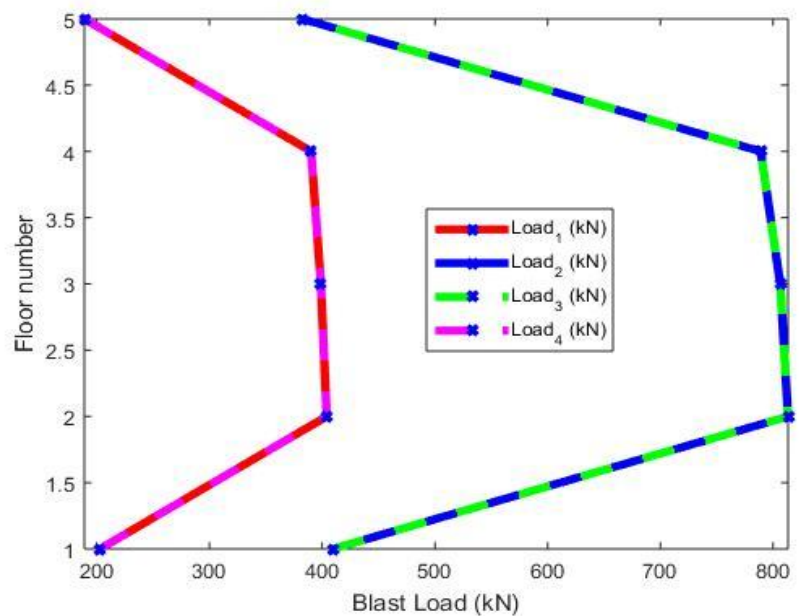

Fig.7. (a) Load vs floor number for case 2
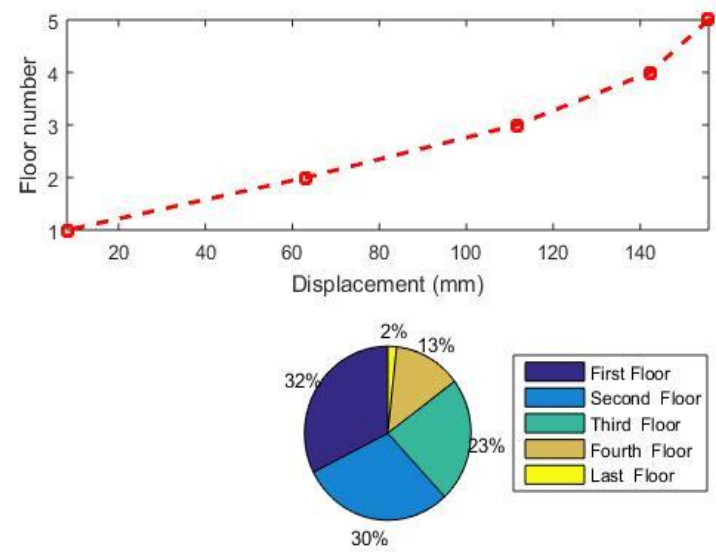

Fig. 7. (b)Displacement vs floor for case 2

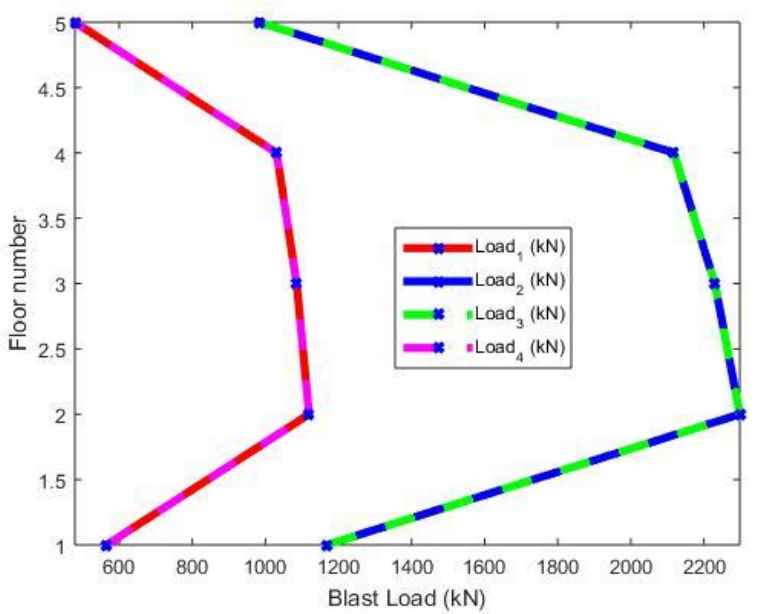

Fig.8. (a)Load vs floor number for case 3
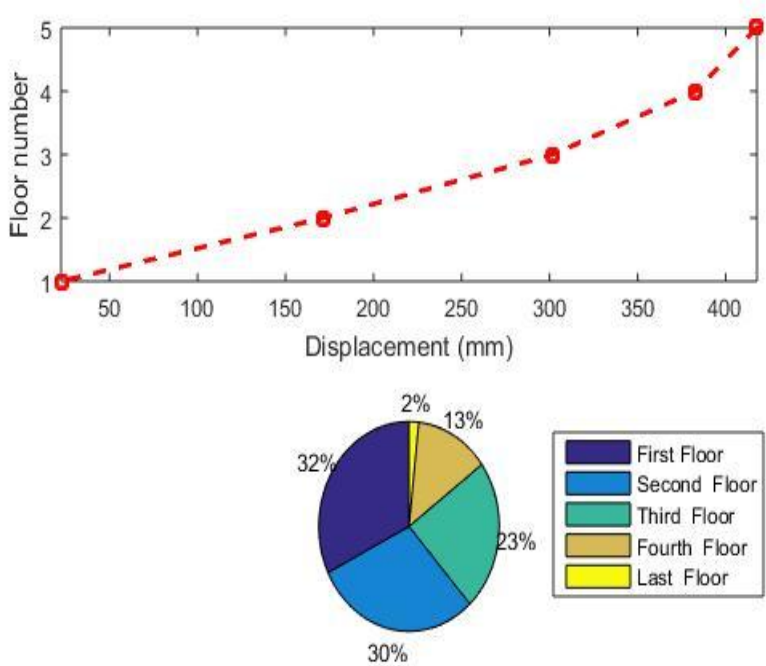

Fig.8. (b) Displacement vs floor for case 3 


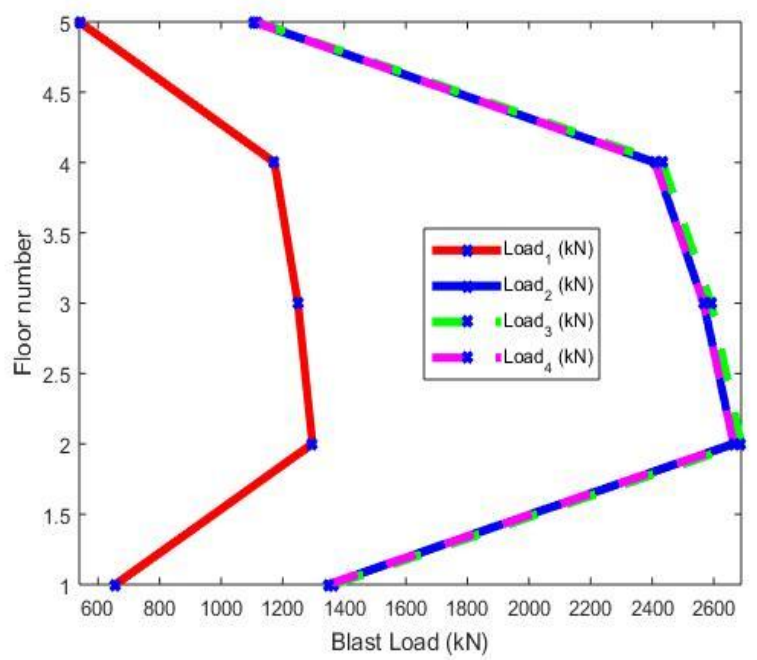

Fig.9. (a)Load vs floor number for case 4
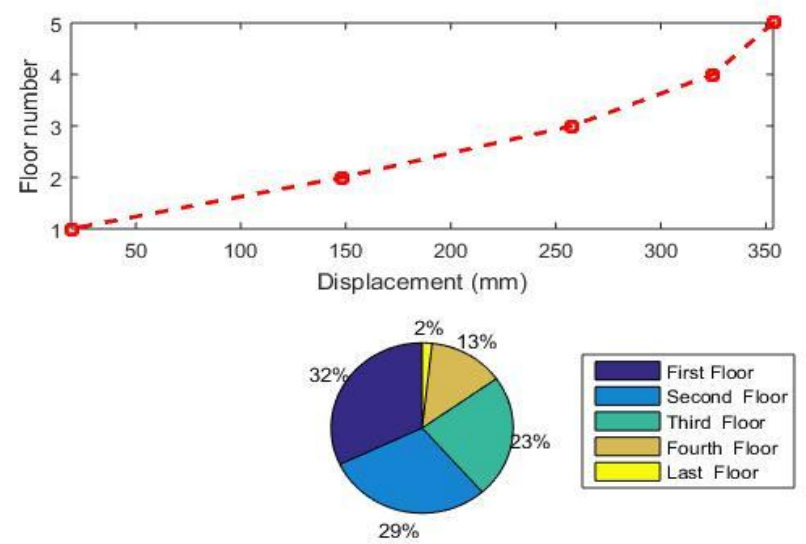

Fig.9. (b) Displacement vs floor for case 4

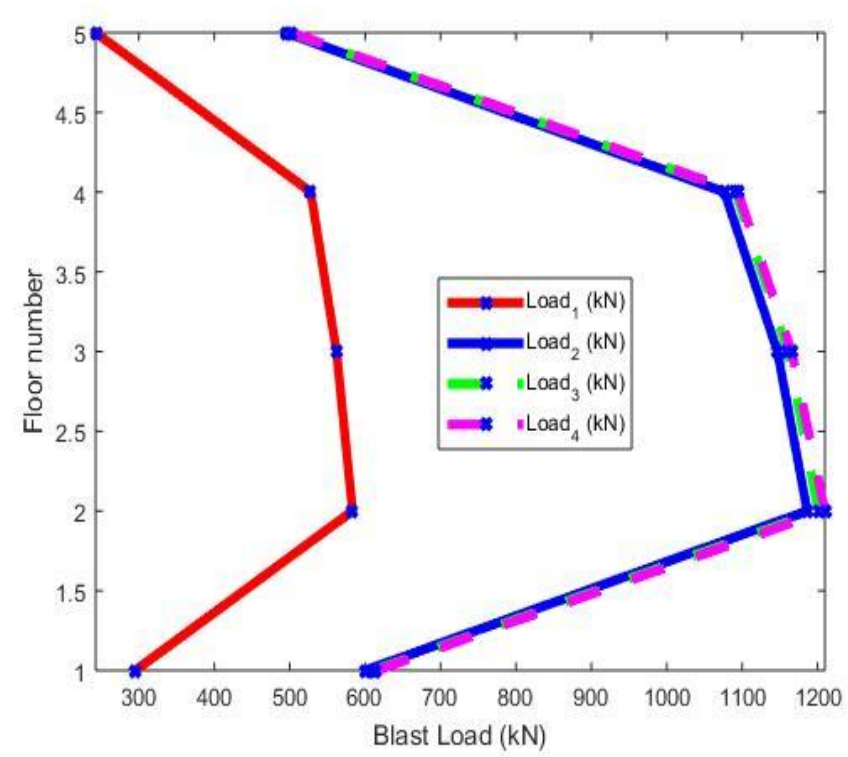

Fig.10. (a) Load vs floor number for case 5
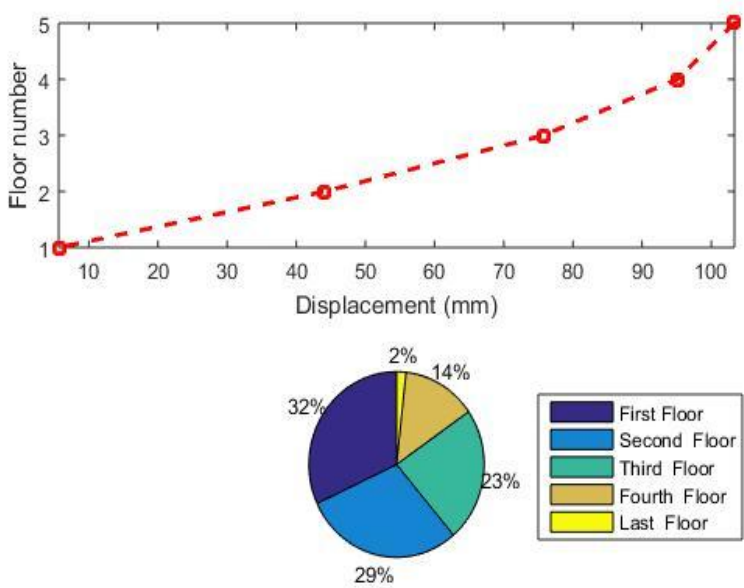

Fig.10. (b) Displacement vs floor for case 5

Maximum storey displacement can be seen in case 1 that is when the distance of explosion is 10 meters from the yield of the explosion is $400 \mathrm{~kg}$ but when the standoff distance is double by making the yield of explosion constant then the maximum displacement is reduced to $160 \mathrm{~mm}$ from maximum displacement. When the yield of the explosion is half that is $200 \mathrm{~kg}$ by making the standoff distance same $(10 \mathrm{~m})$ then the maximum displacement is around $425 \mathrm{~mm}$. Without altering the column and beam dimension, increasing the stiffness of the structure by increasing the bays from three bay of four-meter to four bays of threemeter and three bays of four-meter to six bays of two-meter in both directions then the maximum displacement is $350 \mathrm{~mm}$ and $105 \mathrm{~mm}$, respectively.

\section{Conclusions}

The purpose of developing this program is to study the effect of explosive loads on reinforced concrete columns. The test procedure included reinforced concrete columns with various transverse steel components that were subjected to open-air explosion tests at the Indian Forces Base and equipped with pressure gauges, tendon potentiometers and strain gauges. The pressure time and movement time of the column are recorded and displayed. The shear force enhances the part effect, the proportional distance effect, and the axial load effect. This relationship is analysed by comparing the failure and failure modes and displacement characteristics of traditional cylinders, RCC cylinders and cylinders designed 
as part of the shear load system structure. Regardless of the type of column is ordinary, seismic or RCC, the response of concrete columns cannot withstand the $0.22 \mathrm{~m} / \mathrm{kg} 1 / 3$ scale distance. The larger the scale distance, the smaller the degree of damage. When the maximum lifting height is $0.86 \mathrm{~m} / \mathrm{kg} 1 / 3$, the responses of all columns are relatively the same. In the test with a scale distance of $\mathrm{z}=0.22 \mathrm{~m} / \mathrm{kg} 1$, the influence of cross-sectional details and seam overlap is obvious. Strip the concrete of the traditional column and cut the column into two parts. In the seismic column, only the concrete cover is crushed and split. The concrete core has been well restrained; the tightly spaced sections of the transverse steel bars increase the impact resistance of the pillars, especially at smaller distances. Therefore, pillars with seismic components have higher explosion resistance than pillars with conventional components.

\section{Reference}

[1].T. Ngo et al. (2007). Blast loading and blast effects on structures-an overview. Electronic Journal of Structural Engineering.

[2].T. Ch. Madhavi1 et al. (2016) Effects of Temperature on Concrete, Department of Civil Engineering, SRM University, VOL. 11, NO. 9, 2016 ISSN 1819-6608, ARPN Journal of Engineering and Applied Sciences.

[3].IS 4991 - 1968 (Reaffirmed 2003) Criteria for Blast Resistant Design of Structures for Explosions above Ground.

[4]. Kirk A. Marchand, et al. (2005), "Blast and Progressive Collapse" fact for Steel Buildings, USA.

[5].Annelies De Wit et al. (2011), Behavior and Structural Design of Concrete Structure Exposed to Fire, Master of Science Thesis Stockholm, Sweden.

[6].EN 1994-1-2 (2005): Eurocode 4: Design of composite steel and concrete structures - part 1-2: General rules - Structural fire design

[7].Alexander M. Remennikov et al. (2003) "A review of methods for predicting bomb blast effects on buildings," Journal of battlefield technology.

[8].Abdelkrim Kadid et al. (2008) "Stiffened plates subjected to uniform blast loading," J. Civ. Eng. Manag.
[9].Ming-Wei Hsieh, Jui-Pin Hung and De-Jen Chen (2008), "Investigation on the blast resistance of a stiffened door structure," J.M. S. T.

[10].T. Borvik et al. (2011) "Response of structures to planar blast loads - A finite element engineering approach" Computers and Structures.

[11].Saeed Ahmad (2012) "Effects of impulsive loading on reinforced concrete structures" University of Engineering \& Technology Taxila.

[12].A.R. Mortezaei (2011) Risk reduction and externally FRP retrofitting of RC columns subjected to extreme loading conditions, Islamic Azad University,

[13].Professor M. R. Wakchaure and Seema T. Borole (2013) Comparison of maximum stress distribution of long and short side columns due to blast loading.

[14].Sam E. Rigby et al. (2014) The Negative Phase of the Blast Load, The University of Adelaide, SA 5005, Australia.

[15].John M. Biggs. Introduction to Structural Dynamics, $2^{\text {nd }}$ Edition.

[16].Saeed Ahmad et al. (2013)., Design Considerations for Blast Resistance of Architectural Precast Concrete Façades PCI's Architectural Precast Concrete Services Committee discusses items to consider in designing for blast resistance.

[17].Zubair I. Syed et al. (2016)., International High- Performance Built Environment Conference - A Sustainable Built Environment Conference 2016 Series (SBE16) Performance of Earthquake-resistant RCC Frame Structures under Blast Explosions

[18].Gautham T N et al. (2017)., International research journal of engineering and technology blast resistant buildings

[19].Abdulaziz Kassahun et al. (2017)., Blast loading and blast effects on RC frame buildings addis ababa institute of technology school of graduate studies.

[20].FEMA 426, Reference Manual to Mitigate Potential Terrorist Attacks against Buildings, Risk Management Series, Federal Emergency Management Agency, Department of Homeland Security, USA, and December 2003. 
[21].Agnihotri, A., Jethoo, A.S. and Ramana, P.V., (2021) Mechanical and Durability Analysis of Recycled Materials. In Key Engineering Materials (Vol. 882, pp. 228-236). Trans Tech Publications Ltd.

[22].Ayush Meena, P.V. Ramana (2021)., Assessment of structural wall stiffness impact due to blast load Materials Today: Proceedings, Elsevier Publication.

[23].Ramana, P. V., Surendranath Arigela, and M. K. Shrimali. "The Health Monitoring Prescription by Novel Method." Advances in Structural Engineering. Springer, New Delhi, 2015. 2587-2598. 